\title{
Frequency demodulation on otolith numerical images for the automation of fish age estimation
}

\author{
Hervé Troadec \\ IFREMER, Cientre de Brest, B.P. 7o, 29280 Plouzané, France. \\ Unité de Recherches en Biomathémaliques el Biostatistiques, liniversité Paris-VII, tour 53, 2, place Jussieu, 75251 Paris Cedex 05, France.
}

Received March 25, I991; accepted August 26, I 991.

Troadec H. Aquat. Living Resour., 1991, 4, 207-219.

\begin{abstract}
A method to assist the reading of calcified structures with digital images is proposed. An a priori growth pattern is introduced in the image processing to take into account both the variability of the ring size and the non-linearity of their growth. The introduction of biological knowledge is performed within a demodulation processing using the reciprocal growth function. The ring number is estimated by spectral analysis. The constraints introduced by the growth model are weak since they are restricted to the definition of $\mathrm{L}_{0}$, in the case of an exponential model, or of $\mathrm{L}_{x}$ in the case of a Von Bertalanffy model. When applied to larval Dover sole otoliths (Solea solea) results close to the expert's are obtained. In the case of saithe otoliths (Pollachius virens) the mean discrepancy with the expert's, i.e. 1.5 years, can be assigned to the lack of processing of marginal rings and to the inadequacy of the morphogenesis model on which the processing algorithm is based. This approach which is only founded on the dynamic features of the "biological signal", will have to be completed in future work with the introduction of structural information.
\end{abstract}

Keywords : Otolith, digital image, age, growth, Solea solea, Pollachius virens.

Automatisation de l'estimation de l'âge des poissons au moyen de démodulation de fréquence sur des images numériques d'otolithes.

Résumé

Une méthode d'aide à la lecture de pièces calcifiées par traitement d'images numériques est proposée. Un modèle de croissance a priori est intégré dans le traitement de l'image afin de prendre en compte à la fois la variabilité de la taille des « anneaux » et la non linéarité de leur croissance. Cette intégration est réalisée dans un traitement de démodulation à l'aide de la loi de croissance réciproque. L'estimation du nombre d'anneaux est ensuite réalisée par analyse spectrale. Les contraintes introduites par la prise en compte du modèle sont faibles puisque limitées à la définition du $\mathrm{L}_{0}$, dans le cas d'un modèle exponentiel, ou du $\mathrm{L}_{\infty}$ dans le cas d'un modèle de Von Bertalanffy. Appliquée à des otolithes de larves de soles (Solea solea) cette méthode permet d'obtenir des résultats proches de ceux de l'expert. Dans le cas des otolithes d'adultes de lieu noir (Pollachius virens), la différence moyenne de 1,5 ans avec les experts doit être imputée à l'absence de traitement adéquat des anneaux marginaux tant qu'à l'inadéquation du modèle de morphogenèse sur lequel repose l'algorithme de traitement. Cette approche, uniquement fondée sur les caractéristiques dynamiques du "signal " biologique, devra être complétée par la prise en compte d'informations structurelles auxquelles se réfèrent habituellement les lecteurs.

Mots-clés : Otolithe, image numérique, âge, croissance, Solea solea, Pollachius virens. 


\section{INTRODUCTION}

\section{Reading of calcified structures}

It is essential to read calcified structures (C.s.) to gain knowledge of the demographic structure of fish populations. Most of the fisheries laboratories involved in fish stock assessment are concerned with this tedious activity. Since the first paper of Lea (1910), very little work has been done on the methodology of C.s. reading. However, from the 1960 s, there has been renewed interest in research on C.s. reading methodologies.

This new initiative was sparked in part by international workshops on C.s. reading convened by ICES (Anon., 1960; Kohler, 1964). These programmes aimed at comparing species specific reading methodologies and, after technical recommendations, at agreeing upon a standard reading terminology (Jensen, 1965; Everson, 1980). The Atlantic salmon scale reading working group (Anon., 1984, 1988) extended this standardization to reduce both the intra and interreader variability. This approach converged on a quasi-algorithmic structure for C.s. reading, which paralleled the more theoretical works of cybernetic approaches with C.s. reading (Sych, 1974).

However, the ageing laboratories encountered a more complex situation linked to the unavoidable and necessary compromise between age reading reliability, the human factor and the duration of the processing. The motivations of ageing laboratories for using computer readings are multiple, and concern:

- Quantification (counting and measurement). This is where the human operator is most limited compared with computers.

- Interpretation. This leads to the substitution or the assistance of a powerful reading scheme (mathematical models, logic).

- Reproductibility. The reduction of the intrareader variability is essential for the improvement of the age determination reliability.

- Knowledge preservation (Expert domain). The lack of knowledge transfer between readers, mainly on critical species, can have long-term effects on fisheries statistics.

Age reading on C.s. is a visual perception excrcise whose methodology is based on the validation of interpretation rules on a training set and then on the extrapolation of these rules to the whole population, hence the recourse to pattern recognition techniques.

\section{Assistance and automation of calcified structure reading}

At first, it was suggested that computers be applied to the reading process in an auxiliary way such as for measurement recording. Mason (1974) described a semi-automatic system for recording the scale structures of chinook salmon (Oncorhynchus ishawytscha) for stock discrimination. More recently, the spread of microcomputers and low-priced digitizing boards, allow numerous marine laboratories to have access to these techniques, albeit not differing significantly from Mason's machine (Frie, 1982; Messieh and McDougall, 1985; McGowan et al., 1987; Tzeng and $\mathrm{Yu}, 1988$ ). Recourse to pattern recognition techniques is motivated by the search for interpretative information to assist or even supersede the reader. Goncharov and Smetanin (1974) proposed a microphotometric recording of scale circuli and Vasil'kov (1977) introduced spectral analysis in a growth rhythms study on Cheilodactylus macropterus. Since 1971, the NEAFC (NMFS, Woods-Hole) has sub-contracted work on the automation of age reading with universities involved in the NASA programmes (MIT) or specialized in pattern recognition (Virginia Polytechnic Institute). Two methods could be distinguished, one based on a topological approach, where each ring is identified individually, and the other one, based on a spectral approach, where the global frequency composition is processed. Despite these research efforts, no successful technique was found. All these attempts ignored the growth dynamics inherent in the morphogenesis of C.s. The researchers either literally reproduced the reader's reading scheme or applied unmodified processing algorithms which were successful in other fields, or unfortunately, both.

Hirschhorn and Small (1987) made the first attempt at using the biological knowledge of the growth process. After a manual digitization, they fitted the presumed position of the scalc rings to a Von Bertalanffy growth model. Each ring was accepted or rejected by examination of the fitting residuals. In this paper we propose a processing scheme leading first to an automatic data acquisition and then'to the introduction of a growth pattern function in C.s. information processing. We apply this spectral method to at hatchery and in situ sample of Dover sole, Solea solea, larvae sagittae and to an adult saithe, Pollachius virens, sample.

\section{MATERIAL AND METHODS}

Video images were acquired with a video camera (Sony, M3A, 768 lines) mounted on a compound microscope (Leitz, Diaplan) for Dover sole otoliths and on a binocular microscope (Wild, M5A) for the saithe otoliths. Digitizing and processing of otolith images were carried out on a TRIDYN station (INF'OROP). The digital images had a $512 \times 512$ pixels resolution with 256 gray levels. The C.s. processing software was developed in FORTRAN 77 with the TRIMAGO image processing library (IFREMER). 


\section{Dover sole larvae otoliths}
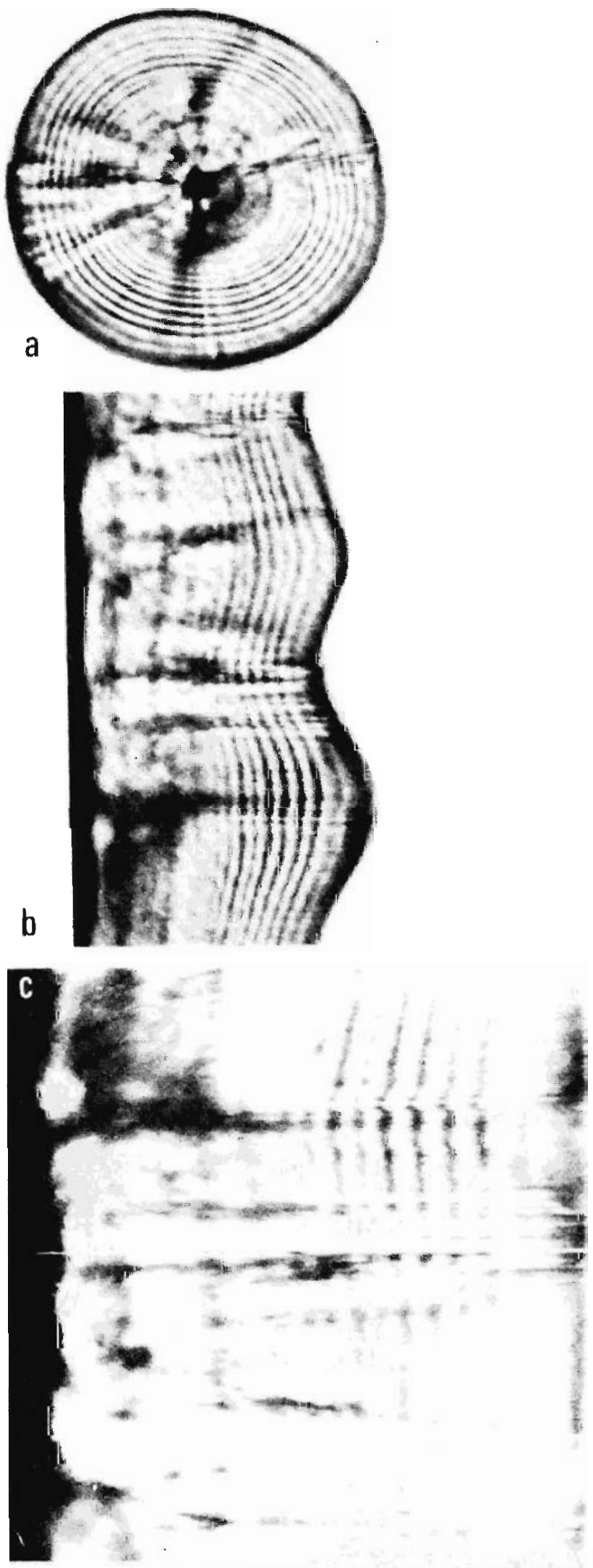

The sample used for the blind reading $(N=26)$ comes from a control sample described in Lagardère (1989). The larvae were reared in a hatchery from eggs spawned by captive Dover sole at the IFREMER center, Brest, in March-April 1987. The eggs were incubated at a temperature of $12^{\circ} \mathrm{C}\left( \pm 0.6^{\circ} \mathrm{C}\right)$ and with a 12:12 photoperiod. After hatching, they were fed once per day with Artemia nauplii. The fish size ranges from 6.66 to $10.33 \mathrm{~mm}$.

The second sample $(\mathrm{N}=25)$ originates from an in situ sampling (SOLDET, VII-April 87) collected in the Bay of Biscay. The fish size ranges from $7.83 \mathrm{~mm}$ to $11.04 \mathrm{~mm}$.

The otoliths (sagittae and lapilli) were mounted, in toto, in "Permount" on a cover slip and observed under transmitted light with a magnification of $1000 \mathrm{x}$. Resolution of the image was limited by the resolution of the microscope, which was approximately $0.28 \mu \mathrm{m}$, and not by the digitizing process whose resolution was approximately $0.04 \mu \mathrm{m}$.

\section{Saithe otoliths}

Saithe otoliths $(\mathrm{N}=58)$ were obtained from fish originating from the ICES division VI-A, and were sampled on the Lorient fishmarket as part of the routine fishing survey. First, the otoliths were washed with clear water and then embedded in epoxy resin as described in Souplet and Dufour (1983). The fish size ranges from 45 to $95 \mathrm{~cm}$.

\section{Data Acquisition}

The widespread method of image data acquisition on C.s. is based on radial extraction (BIOSONICS OPRS, 1985; Neal, 1986; Hirschhorn and Small, 1987). All these authors reduce the data acquisition to a single radial line and so ignore bidimensional information. A classical line by line image processing (or scanning) will ignore that an oriented space is considered, that is why we propose a generalization of the image representation to polar coordinates (fig. 1). This being a time-consuming process, we have proposed a synthetic radial computation, $\mathrm{P}(r, \theta)$, (Troadec and Prouzet, 1986) which is supposed to integrate C.s. information over a region of interest and be less sensitive to local discontinuities of rings. Let us suppose the synthetic radial computation of an image $f(x, y)$. It could be expressed by the mean estimator:

$$
\mathbf{P}(r, \theta)=\mathrm{E}\left[f\left(r, \theta_{i}\right)\right]=\mathrm{E}\left[f\left(x \cos \theta_{i}, \operatorname{Arctg} y / x\right)\right] .
$$

with $r$ the C.s. radius and $\theta_{i}$ the angular parameter of the $i$ th radial.

Figure 1. - Dover sole sagittae $(a)$ rough image $(1 \mathrm{~cm}=7 \mu \mathrm{m})$, (b) same image in polar representation $(1 \mathrm{~cm}=5.7 \mu \mathrm{m})$ and (c) in standardized polar representation. 
The median estimator is preferred to the mean estimator because the latter has a great sensitivity to distribution tails and gives:

$$
\mathrm{P}(r, \theta)=\underset{\theta}{\operatorname{Median}}\left[f\left(r, \theta_{i}\right)\right] .
$$

The method used here acts in two phases:

1. Image radial extraction and distance standardization according to the C.s. edge;

2. Information compression by a median radial computation over the region of interest.

\section{Data Processing}

In practice, classical numerical image filtering is the result of the interaction of a constant size kernel with the image pixels (clementary image points) either by linear or morphological convolution. Consequently this kind of filter operates in a constant and narrow frequency or spatial domain, which does not always cover all the otolith's structurc. Recourse to these kinds of euclidian filters, designed to preserve translation invariance, results in underestimations of the C.s. ring number count (Troadec, 1992), insofar as it does not take into account the decreasing size of the rings.

\section{The structuring function}

A recent evolution of euclidian image processing towards a weakening of filter properties (translation, rotation and homothetic invariance) was exposed in Serra (1986). Beucher et al. (1988), in a road traffic analysis application, associates a $\theta$ function to the image, in the form of a perspective transform. In this example, the mathematical morphology will associate an anamorphosis transform to a structuring function $\theta_{(B \times)}$ by conditioning the structuring element $\mathrm{Bx}$ to a non-euclidian space. Reciprocally, the inverse transform $\theta$ can be applied to the image in order to come back to the euclidian space (fig. 2).

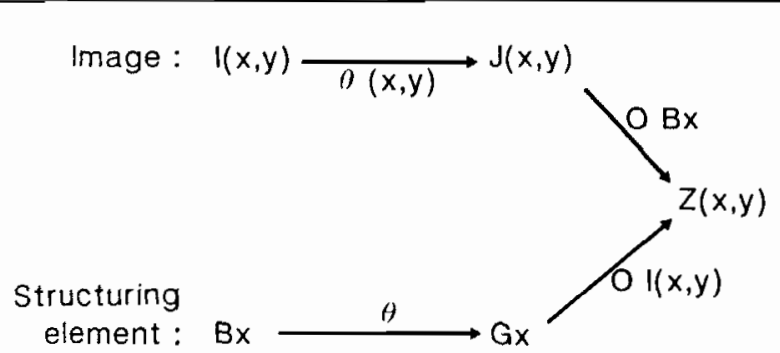

Figure 2. - Use of the structuring function $\theta$ for image processing. $\mathrm{I}(x, y)$ is the original image, $\mathrm{J}(x, y)$ the demodulated image and $Z(x, y)$ the filtered image. $O$ is the morphological convolution operator.

\section{Anamorphosis}

Anamorphosis, which is one of the most common preprocessing transforms, either in numerical analysis or in image processing, transforms data point by point according to a monotone and bijective law (for example, the logarithmic transform). The otolith structure, made of concentric rings in turn opaque and hyalin, appears on the image as a succession of peaks and valleys, which can be simulated by a periodic function. The image gray levels, G, can be expressed by:

$$
G(r)=\sin (2 \pi \exp [\mathrm{K} r]),
$$

$r$ is the space parameter and $\mathrm{K}$ a growth coefficient.

This expression corresponds to the frequency modulated function:

$$
\mathrm{G}(r)=\sin [2 \pi \theta(r)],
$$

where

$$
\theta(r)=\exp [K r]
$$

In this case, the frequency demodulation will be obtained by an anamorphosis with the reciprocal function, expression of time versus frequency:

$$
\gamma(r)=(\log n r) / K
$$

The demodulation of the signal will be obtained referring to [4] by (see fig. 4):

$$
\mathrm{G}(r)=\sin [2 \pi \theta(\theta(r))]=\sin [2 \pi r],
$$

\section{Growth structuring function}

Let us suppose that a C.s. grows according to a Von Bertalanffy growth function (VBGF). The sizc of the C.s. along its major axis, $L_{t}$, will be expressed as a function of time by:

$$
\mathrm{L}_{t}=\mathrm{L}_{\infty}\left[1-\exp \left(-\mathrm{K}\left(t-t_{0}\right)\right)\right],
$$

where $\mathrm{L}_{x}$ is the asymptotic size, $\mathrm{K}$ the Brody growth coefficient and $t_{0}$ is the time where the length is zero. In the case of a Von Bertalanffy growth curve the structuring function will be (fig. 4):

$$
\widehat{\theta}=\left(\operatorname{Logn}\left[\left(\mathrm{L}_{x}-\mathrm{L}_{t} / \mathrm{L}_{\alpha}\right]-\mathrm{K} t_{0}\right) /-\mathrm{K},\right.
$$

Check identification (Nucleus, Hatch, Mouth opening)
Edge detection $\rightarrow \mathrm{E}$
$\begin{gathered}\downarrow \\ \text { Synthetic radial computation }\end{gathered}$
Trend and band-pass filtering $\rightarrow \mathrm{P}_{f}(r, \theta)$
$\downarrow$
Fourier transform $\rightarrow \mathrm{P}_{S}(\mu, v)$
$\downarrow$
Spectral analysis $\rightarrow \hat{a}$
$\downarrow$
$\mathrm{K}$ back-calculation $\rightarrow \mathrm{K}$

Figure 3. - The spectral method algorithm. 
The same reasoning can be made for an exponential growth function, used for the Dover sole larvae by Lagardère (1989):

$$
\begin{gathered}
\theta=\mathrm{L}_{0} \times \exp (\mathrm{K} \times t), \\
\theta=\left[\operatorname{Logn}\left(\mathrm{L}_{t} / \mathrm{L}_{0}\right)\right] / \mathrm{K},
\end{gathered}
$$

\section{Ring number estimation}

The ring number is estimated by spectral analysis. The Fourier transform of the demodulated function will display a major spectral peak whose frequency gives the number of signal cycles, Nc (fig. 4). Let $\mathrm{F}$ be the Fourier transform of a $f$ function, the signal spectrum is calculated by:

$$
\mathrm{F}(v)=\sum_{-\infty}^{+\infty} f(t) e^{-2 \pi i v t},
$$

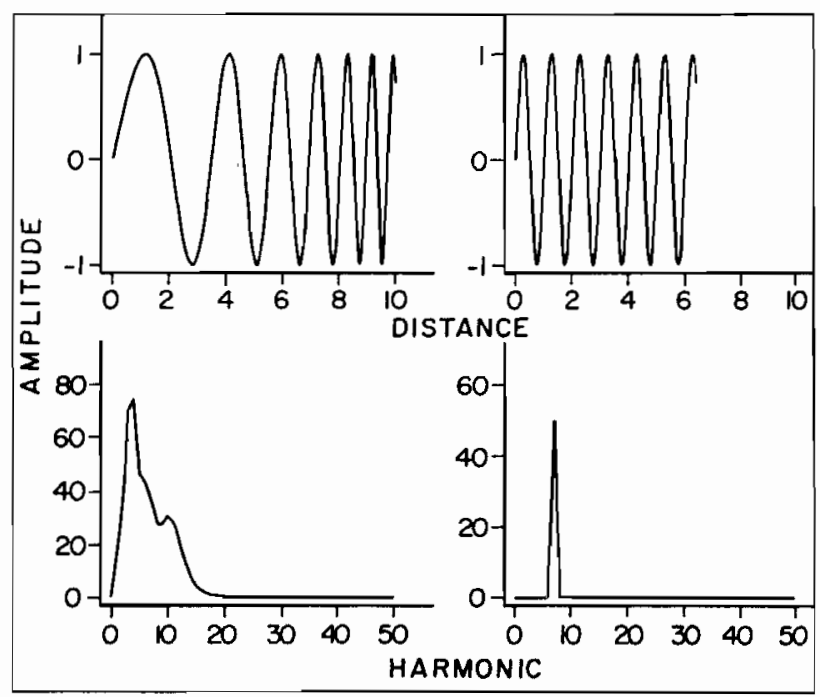

Figure 4. - Von Bertalanffy frequency modulated sine function and anamorphosed sine function in spatial and frequential representation.

where $v$ is the frequency $\left(t^{-1}\right)$. The number of cycles is estimated by the extraction of the major peak of the energy spectrum, $\Phi_{\mathrm{F}}(v)$ :

$$
\Phi_{F}(v)=|F(v)|^{2},
$$

where, $\mathrm{Nc}=\mathrm{N} \times v \max$, with $v \max =v_{t}$ of the major peak and $\mathrm{N}$ is the signal length.

The general algorithm of the spectral method is presented in figure 3.

\section{Variability of parameters}

The use of the reciprocal function for signal anamorphosis implies the knowledge of the modulating function parameters. In the case of a VBGF (Von Bertalanffy Growth Function), only the asymptotic

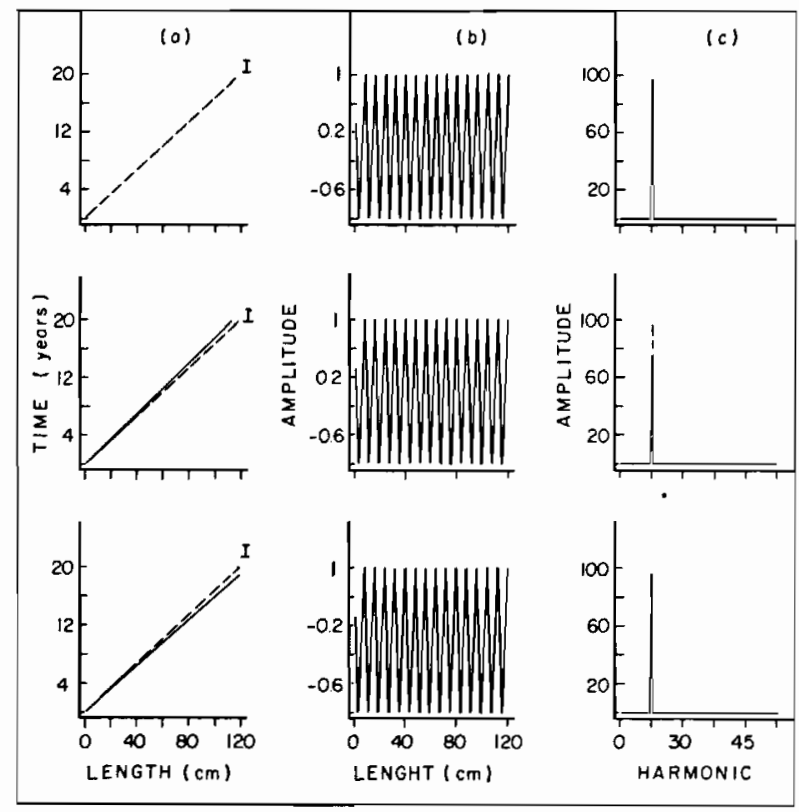

Figure 5. - Result of a $\mathrm{K}$ error on the spectral representation $\left(\varepsilon_{\mathrm{K}}=0,-50 \%,+50 \%\right)$. (a) $\theta \theta$ function (I is the identity function), (b) anamorphosed periodic function, (c) amplitude Fourier spectrum.

parameter, $\mathrm{L}_{\alpha}$, has an effect on the pattern conditioning of the reciprocal function, when the $\mathrm{K}$ coefficient is only a scaling factor. Considering the ring estimation method previously described, which is a relative estimation of the number of cycles in a constant-sized signal, the effect of a homothetic factor is zero ( $f i g .5$

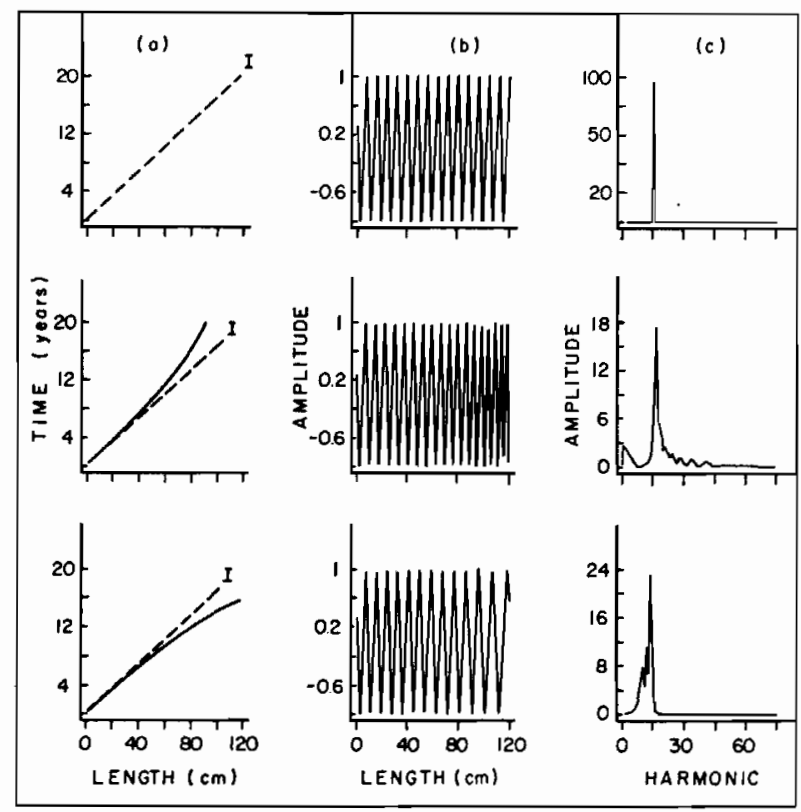

Figure 6. - Result of a $\mathrm{L}_{x}$ error on the spectral representation $\left(\varepsilon_{\mathrm{L}_{\infty}}=0,-10 \%,+10 \%\right)$. (a) $\gamma_{0}$ function ( $\mathrm{I}$ is the identity function), (b) anamorphosed periodic function, (c) amplitude Fourier spectrum. 

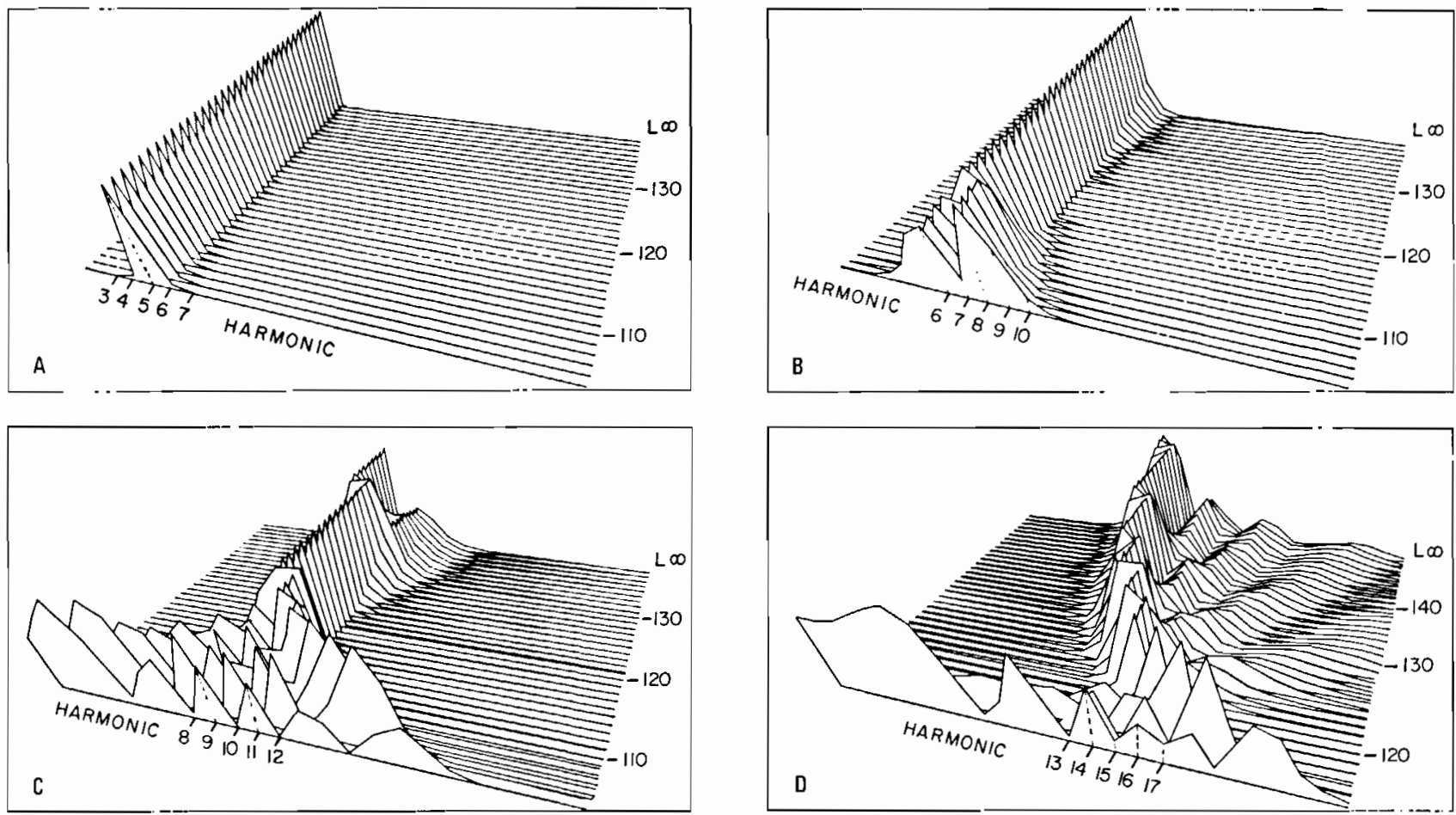

Figure 7. - Influence of a $\mathbf{L}_{x}$ error on the amplitude Fourier spectrum on a $(a) 5,(b) 8,(c) 10$ and $(d) 15 \mathrm{cycle}$ simulated signal $\left(\mathrm{L}_{x}=120 \mathrm{~cm}\right.$, $\mathrm{K}=0.2, t_{0}-0$ ).

and 6). Conversely the effect of an error on $\mathrm{L}_{x}$, will induce a curvature modification and so a ring counting error. This can be visualized by the study of the $\theta \theta$ function. The intensity of the departure from a true $\mathrm{L}_{x}$, will condition the age error value. The effect of a $L_{x}$, error in the structuring function on the signal spectrum was simulated with the $G(t)$ function [7]. The results of the simulation show (fig. 7) an increasing and asymmetrical influence of the errors on $L_{x}$ with the number of signal cycles. The influence is almost imperceptible in the case of a 5-cycle signal and ranges to a shift of a full harmonic for a $4 \mathrm{~cm}$ $\mathrm{L}_{x}$ error on a 15-cycle signal.

\section{RESULTS}

\section{Dover sole larvac otoliths .}

\section{Practical data acquisition}

- A zone of wide $(1 \mu \mathrm{m})$ and low-contrast increments, $\mathrm{I}_{w 1}$, from the hatch check, $\mathrm{H}$, to the mouthopening check, M. After hatchery observation, the time between hatch and mouth opening is estimated at 3 days ( \pm 0.5 days).

- A zone of exponential growth increments, from the mouth opening check (M) to the edge: which could be divided into two subzones. The first subzone, $I_{t 1}$, represents a period of starvation after yolk sac assimilation and before first active feeding. It is char- acterized by thin and low-contrast growth increments and it is where most of the counting errors are made. The second subzone, $I_{h}$, is associated with the first active feeding. It is characterized by high contrast increments.

The expert methodology consists of estimating the total age, $a_{x}$, in three steps:

$$
\hat{a}_{x}=\mathrm{N}_{w 1}+\mathrm{N}_{t 1}+\mathrm{N}_{h} \text {, }
$$

with $\mathrm{N}_{w 1}, \mathrm{~N}_{t 1}$ and $\mathrm{N}_{h}$ the increment count of the $\mathrm{I}_{w 1}$, $\mathrm{I}_{t 1}$, and $\mathrm{I}_{h}$ zone, respectively.

The algorithmic procedure estimates the age, with a synthetic radial from the mouth-opening check to the otolith's border with an offset, $t_{0}$, of 3 days. Indeed, the otoliths seem to have an exponential monotone growth only after mouth opening. Before, the growth rate appears to be approximately twice as much. So the spectral method age estimation, $\hat{a}_{s}$, will be expressed by:

$$
\hat{a}_{s}=\mathrm{N}_{c}+\mathrm{N}_{0},
$$

where $N_{c}$ is the increment count, $N_{0}$ is the increment number at the origin of the counts (assuming one increment per day).

The signal is integrated, as described in [2], in a zone between 10 and 20 degrees with a 1 degree pitch. The zone is selected by the user. Then, integration is performed automatically, and the otolith edge is also automatically extracted with a gradient computation 


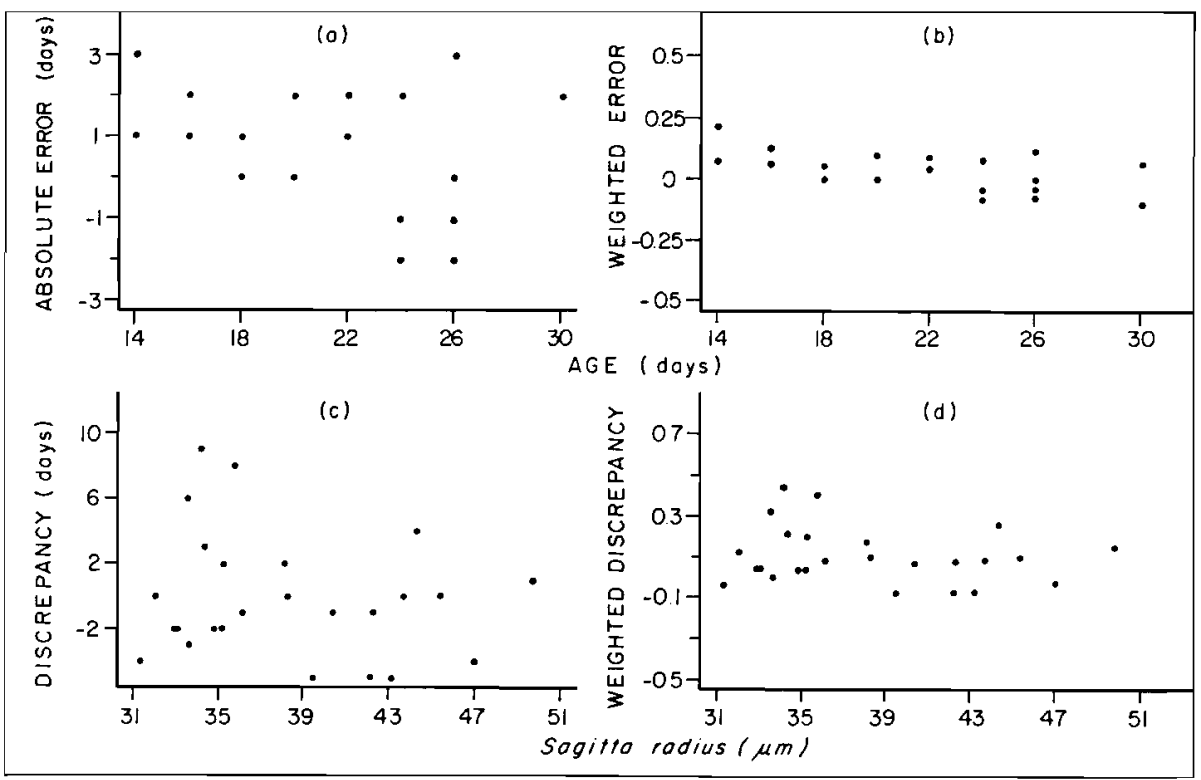

Figure 8. - Dover larvac. Age rcading absolute error $(a)$ and weighted crror $(b)$ on control sample and age reading discrepancy between expert source and spectral method (c) and weighted discrepancy $(d)$ on in situ sample.

which enables the otolith radius measurement. Then, the signal is anamorphosed with the reciprocal function of the growth law [11] and the ring number is estimated with the frequency spectrum as described above. The growth pattern of equation 11 only depends on the $\mathrm{L}_{t} / \mathrm{L}_{0}$ ratio, $\mathrm{K}$ just acts as a homothetic factor. For each individual, $L_{t}$ and $L_{0}$ are automatically measured. This gives an individual structuring function. The most time-consuming phase is the user selection of the reading zone but it never takes more than 30 seconds. Then the automatic processing is realized in 10 seconds, giving a maximum processing time of approximately 40 seconds.

\section{The blind reading}

In order to obtain a method validation, a C.s. blind reading was realized independently with a human expert and the image analysis procedure on the control sample. The knowledge of true age, $a$, on laboratory reared larvae gives the ability to test a blind reading of the otolith. Thereby we processed the error terms, $e_{t}$, instcad of absolute age, $a_{s}$ :

$$
\hat{e}_{t}=a-\hat{a}_{\mathrm{s}}
$$

The crror distribution (fig. 8 and table 1$)(\mu=0.31$, $\sigma=1.69)$ shows a trend towards over estimation of the age of individuals under 20 days $(\mu=1$ day) and under estimation of the age of those over 20 days $(\mu=-0.29$ day $)$.

\section{In situ Dover sole larvae otolith}

The method was then applied to the Dover sole in situ sample. In this case the age was estimated with

Table 1. - Results of blind reading on a sample of hatchery Dover sole larval otoliths. $\mathrm{R}$ is the otolith radius, a the true age, $\hat{a}_{\mathrm{s}}$ the spectral method ageing source and $e_{t}$ the error.

\begin{tabular}{|c|c|c|c|c|c|c|c|c|c|}
\hline $\mathrm{N}^{\circ}$ & $\begin{array}{c}\mathrm{R} \\
(\mu \mathrm{m})\end{array}$ & $\begin{array}{c}a \\
\text { (day) }\end{array}$ & $\begin{array}{c}\hat{a}_{s} \\
\text { (day) }\end{array}$ & $\begin{array}{c}e_{t} \\
\text { (day) }\end{array}$ & $\begin{array}{c}\mathrm{N}^{\circ} \\
(\mu \mathrm{m})\end{array}$ & $\begin{array}{c}\mathbf{R} \\
\text { (day) }\end{array}$ & $\begin{array}{c}a \\
\text { (day) }\end{array}$ & $\begin{array}{c}\hat{a}_{s} \\
\text { (day) }\end{array}$ & $e_{t}$ \\
\hline 1 & 24.2 & 14 & 15 & 1 & 14 & 45.6 & 22 & 24 & 2 \\
\hline 2 & 25.7 & 14 & 17 & 3 & 15 & 44.3 & 24 & 23 & -1 \\
\hline 4 & 27.7 & 16 & 17 & 1 & 17 & 55.2 & 24 & 26 & 2 \\
\hline 5 & 30.2 & 16 & 18 & 2 & 18 & 59.9 & 26 & 25 & -1 \\
\hline 6 & 31.6 & 16 & 17 & 1 & 19 & 56 & 26 & 24 & -2 \\
\hline 9 & 33.2 & 18 & 19 & 1 & 22 & 71.2 & 26 & 26 & 0 \\
\hline 10 & 33.1 & 18 & 18 & 0 & 23 & 64.2 & 26 & 29 & 3 \\
\hline 11 & 40.3 & 20 & 22 & 2 & 24 & 76.2 & 30 & 27 & -3 \\
\hline 12 & 37.1 & 20 & 20 & 0 & 25 & 79.6 & 30 & 27 & -3 \\
\hline 13 & 40.6 & 22 & 23 & 1 & 26 & 92.5 & 30 & 32 & 2 \\
\hline
\end{tabular}


Tate 2. - Expert and image analysis ageing results on an in situ sample of Dover sole larval otoliths. $\mathrm{R}$ is the otolith radius, $\hat{a}_{x}$ the age from the expert source and $\hat{a}_{s}$ from the spectral method source.

\begin{tabular}{|c|c|c|c|c|c|c|c|c|c|}
\hline$N^{\circ}$ & $\begin{array}{c}\mathrm{R} \\
(\mu \mathrm{m})\end{array}$ & $\begin{array}{c}\hat{a}_{x} \\
\text { (day) }\end{array}$ & $\begin{array}{c}\hat{a}_{s} \\
(\mathrm{~d} a \mathrm{y})\end{array}$ & $\begin{array}{c}\mathrm{D} t \\
(\mathrm{~d} d \mathrm{y})\end{array}$ & $N^{0}$ & $\begin{array}{c}\mathbf{R} \\
(\mu \mathrm{m})\end{array}$ & $\begin{array}{c}\hat{a}_{x} \\
(\mathrm{day})\end{array}$ & $\begin{array}{c}\hat{a}_{\mathrm{v}} \\
\text { (day) }\end{array}$ & $\begin{array}{c}\mathrm{D} t \\
\text { (day) }\end{array}$ \\
\hline 1 & 44.3 & 27 & 23 & 4 & 14 & 32.9 & 25 & 27 & -2 \\
\hline 2 & 49.7 & 27 & 26 & 1 & 15 & 32 & 25 & 25 & 0 \\
\hline 3 & 42.3 & 26 & 27 & -1 & 16 & 36.1 & 25 & 26 & -1 \\
\hline 4 & 39.5 & 26 & 31 & -5 & 17 & 33 & 26 & $2 x$ & -2 \\
\hline 5 & 42.2 & 27 & 32 & -5 & 18 & 34.8 & 25 & 27 & -2 \\
\hline 6 & 43.2 & 27 & 32 & -5 & 19 & 35.1 & 28 & 30 & -2 \\
\hline 9 & 31.3 & 24 & 28 & - & 22 & 34.1 & 27 & 18 & 9 \\
\hline 10 & 33.6 & 24 & 27 & -3 & 23 & 35.7 & 27 & 19 & 8 \\
\hline 11 & 47 & 35 & 39 & -4 & 24 & 33.5 & 28 & 22 & 6 \\
\hline 12 & 43.7 & 35 & 35 & 0 & 25 & 34.3 & 28 & 25 & 3 \\
\hline 13 & 35.2 & 25 & 23 & 2 & & & & & \\
\hline
\end{tabular}

Tatue 3. - Results of three ageing sources on saithe otoliths, Expert $\left(\hat{a}_{x}\right)$, spectral analysis $\left(\hat{a}_{s}\right)$ and counting with the Top-Hat Transform $\left(\hat{a}_{t}\right)$. Fl corresponds to the fish length.

\begin{tabular}{|c|c|c|c|c|c|c|c|c|c|c|c|c|c|c|}
\hline $\mathrm{N}^{\alpha}$ & $\begin{array}{c}\mathrm{Fl} \\
(\mathrm{cm})\end{array}$ & $\begin{array}{c}\hat{a}_{x} \\
\text { (year) }\end{array}$ & $\begin{array}{c}\hat{a}_{\mathrm{s}} \\
\text { (year) }\end{array}$ & $\begin{array}{c}\hat{a}_{t} \\
(\text { year) }\end{array}$ & $\mathbf{N}^{0}$ & $\begin{array}{c}\mathrm{Fl} \\
(\mathrm{cm})\end{array}$ & $\begin{array}{c}\hat{a}_{x} \\
\text { (year) }\end{array}$ & $\begin{array}{c}\hat{a}_{\mathrm{s}} \\
\text { (year) }\end{array}$ & $\begin{array}{c}\hat{a}_{i} \\
\text { (year) }\end{array}$ & $\mathrm{N}^{\circ}$ & $\begin{array}{c}\mathrm{Fl} \\
(\mathrm{cm})\end{array}$ & $\begin{array}{c}\hat{a}_{x} \\
\text { (year) }\end{array}$ & $\begin{array}{c}\hat{a}_{s} \\
\text { (year) }\end{array}$ & $\begin{array}{c}\hat{a}_{t} \\
\text { (ycar) }\end{array}$ \\
\hline I & 65 & 5 & 5 & 3 & 21 & 81 & 6 & 4 & 3 & 41 & 95 & 10 & 10 & 4 \\
\hline 3 & 66 & 5 & 5 & 4 & 23 & 81 & 7 & 5 & 4 & 43 & 44 & 3 & 3 & 2 \\
\hline 4 & 67 & 6 & 6 & 6 & 24 & 72 & 6 & 6 & 4 & 44 & 45 & 3 & 3 & 3 \\
\hline 5 & 67 & 4 & 5 & 5 & 25 & 75 & 5 & 5 & 4 & 45 & 46 & 3 & 3 & 3 \\
\hline 6 & 68 & 4 & 4 & 4 & 26 & 76 & 7 & 5 & 5 & 46 & 46 & 3 & 3 & 2 \\
\hline 8 & 69 & 5 & 4 & 5 & 28 & 77 & 7 & 6 & 6 & 48 & 49 & 3 & 3 & 2 \\
\hline 9 & 70 & 5 & 5 & 4 & 29 & 83 & 7 & 6 & 5 & 49 & 50 & 3 & 3 & 3 \\
\hline 10 & 70 & 6 & 4 & 6 & 30 & 84 & 7 & 6 & 5 & 50 & 49 & 3 & 3 & 2 \\
\hline 12 & 71 & 6 & 5 & 6 & 31 & 84 & 8 & 7 & 4 & 51 & 50 & 3 & 3 & 3 \\
\hline 11 & 70 & 6 & 5 & 5 & 32 & 84 & 6 & 4 & 5 & 52 & 50 & 4 & 3 & 3 \\
\hline 13 & 72 & 5 & 5 & 3 & 33 & 83 & 6 & 7 & 3 & 53 & 50 & 4 & 3 & 2 \\
\hline 19 & 79 & 7 & 6 & 4 & 39 & 95 & 10 & 11 & 5 & & & & & \\
\hline 20 & 79 & 8 & 8 & 6 & 40 & 95 & 9 & 7 & 5 & & & & & \\
\hline
\end{tabular}

an offset of 6 days corresponding to a natural slower growth (Lagardère, pers. comm.) and the estimated age, $\hat{a}_{s}$, is compared with the expert age estimation, $\hat{a}_{s}$, by calculating the ageing discrepancy:

$$
\mathrm{D} t=\hat{a}_{x}-\hat{a}_{s^{*}}
$$

The discrepancy distribution (fig. 8 and table 2) statistics show a mean, $\mu=-0.08$, and a standard error, $\sigma=3.82$ with $N=25$ otoliths.

\section{The Sait'ie ctentin's cose}

In this case, all the rings are well defined but are not complete all around the otolith and the occurrence of checks is very low. The main reading difficulty consists of defining the nature of the edge (opaque or hyalin). According to the expert, the median radial extraction was carried out on the long axis of the otolith. Because of the otolith shape, the integration zone is defined between 5 and 10 degrees with a 0.5 degree pitch. All the rings are to be counted resulting in a simple expression of $\hat{a}_{\mathrm{s}}=\mathrm{N}_{\mathrm{C}}$. The results are presented in table 3. Figure 9 shows the distribution of the differences between Spectral analysis/Expert and Counting/Expert. The counting method shows an increase of variance with length, and a strong trend meaning that reliability decreases with the length of the fish, when the spectral analysis only shows a heteroscedasticity phenomenon.

\section{DHSCUSGLON}

\section{Statistical comments}

Most of the papers devoted to otolith microstructures only considered the absolute error terms. Cam- 


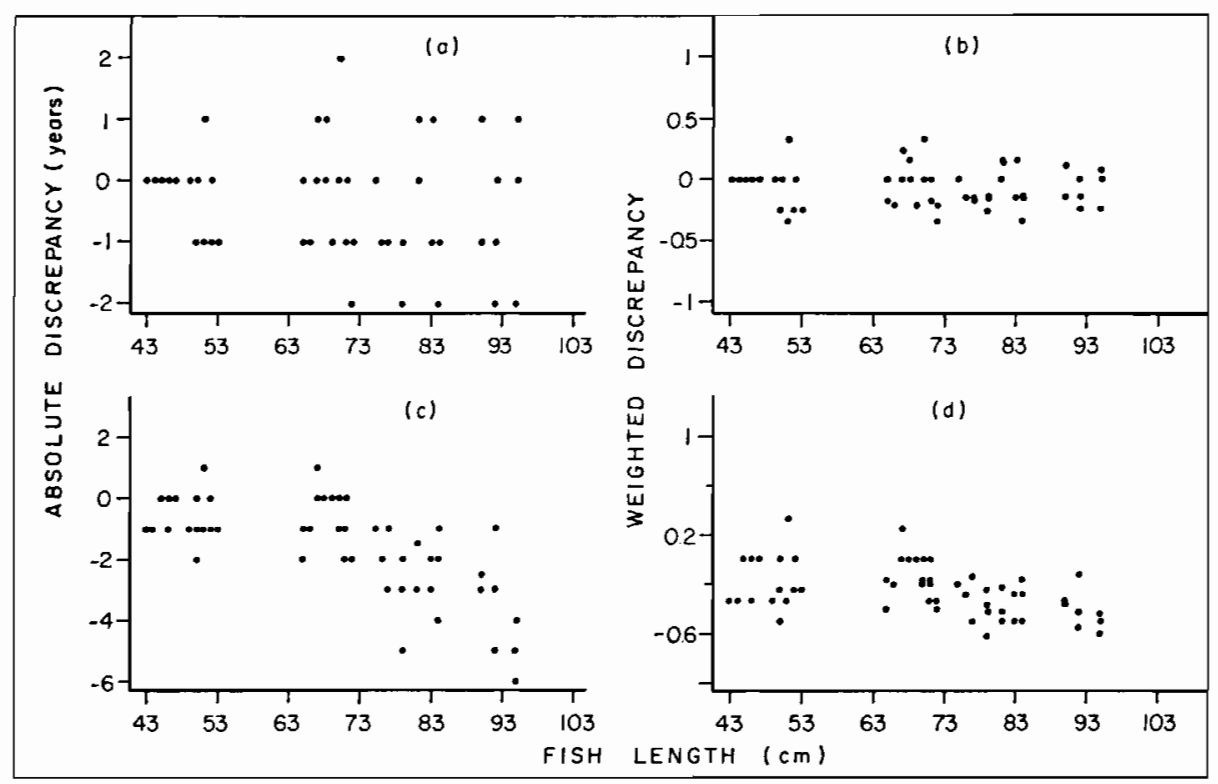

Figure 9. - Adult saithe. Age reading absolute discrepancy $(a)$ and weighted discrepancy $(b)$ between spectral method and expert source on saithe and absolute discrepancy $(c)$ and weighted discrepancy $(d)$ between Top-Hat method and expert source.

pana et al. (1987) noted, on laboratory-reared larval herring, an age-structured pattern in the residuals of a linear model fitted to the absolute discrepancy between increment counts and true age. They concluded that the linear model was inappropriate to the data. As a result we consider the increment count as an estimation of the true age, a, and thereby a statistical approach has to be adopted. The discrepancies, or the errors, between true age and estimated age are induced by different causes, such as otolith preparation, individual growth rhythm or statistical bias. Whatever they may be, these errors should be examined so that better models can be formulated.

\section{Heteroscedasticity, absolute and relative error}

The increase of the age estimation variability with otolith size is currently associated, in the case of larval otoliths, with the absence of polishing as usually done on large otolith (diameter $>40 \mu \mathrm{m}$ ). Indeed, in the case of the Dover sole, the variability shows an increase on and after $40 \mu \mathrm{m}$ radius otoliths. This heteroscedasticity phenomenon is due to the use of the absolute error rather than the relative error. A 5- day error on a 10-day-old individual would not have the same consequences, or the same weight, for example in a growth rate estimation, than the same crror on a 60-day-old one. The solution adopted was to introduce an error weighting. If we assume that $\alpha_{i}$ is the probability of counting an increment, the total probability will be $\sum \alpha_{i}$ and if we assume that $\alpha_{i}$ is constant for each $i$, we can conclude that the total error is dependent on $N \alpha_{i}$. Then, the absolute error will be expressed by $\mathrm{N} \beta_{i}-\mathrm{N}=-\mathrm{N} \alpha_{i}$ (with $\beta_{i}=1-\alpha_{i}$ ) and the relative error by $-\alpha_{i}$. For that reason we transform the absolute error value into a ratio of the total ring number on the control sample. After this transformation, the heteroscedasticity phenomenon is attenuated and only the trend noted above remains. When no true age is available we calculate discrepancy relative to the expert age. This might be a biased true age estimation, but it is the only reference. The equation (16) will be transformed in:

$$
\hat{e}_{t}=\left(a-\hat{a}_{t}\right) / a
$$

The basic statistics of the results are presented in table 4.

Table 4. - Statistics on the weighted distribution of crrors. Sp. An. refers to the spectral analysis and Count. to the Top-Hat processing.

\begin{tabular}{|c|c|c|c|c|c|c|}
\hline & $\mu$ & $\sigma$ & Median & Max & $\operatorname{Min}$ & $\mathbf{N}$ \\
\hline \multicolumn{7}{|c|}{ Blind reading on laboratory-reared Dover sole } \\
\hline Sp. An. & 0.025 & 0.077 & 0.023 & 0.21 & -0.1 & 26 \\
\hline \multicolumn{7}{|c|}{ in situ Dover sole } \\
\hline Sp. An. & 0.0042 & 0.14 & $\begin{array}{l}\quad 0.034 \\
\text { saithe }\end{array}$ & 0.19 & -0.33 & 25 \\
\hline Sp. An. & -0.063 & 0.15 & 0 & 0.33 & -0.33 & 58 \\
\hline Count. & -0.25 & 0.21 & -0.27 & 0.33 & -0.63 & 58 \\
\hline
\end{tabular}




\section{Ageing source comparison}

A Student- $t$ test $\left(\mathrm{H}_{0}: \mu=0\right)$, on the relative errors of the control Dover sole sample between the expert results and the spectral method ageing source, shows no differences between the means $(t=1.62$ with a risk error $\alpha=0.05$ ). The method reliability is estimated by the confidence interval $(\mu \pm t \times \sigma)$ ) for a fixed error risk, $x$ (table 5$)$.

Table 5. - Confidence interval of the spectral method ageing source.

\begin{tabular}{lc}
$x$ & Confidence interval \\
\hline 0.05 & $\pm 16 \%$ \\
0.1 & $\pm 13 \%$ \\
0.2 & $\pm 10 \%$ \\
\hline
\end{tabular}

Once the reliability is estimated, the spectral method is applied on the in situ sample. Under the zero hypothesis $\mathrm{H}_{0}: \mu=0$, the Student $t$ test on the discrepancy Spectral/Expert ageing sources, does not allow us to conclude any difference in the distributions.

The image quality of the saithe otoliths gives the possibility to apply in good conditions a conventional image analysis counting method called Top-Hat transformation, an adaptative filter-based version of the classical method described in most of the C.s. reading automation literature. The Student- $t$ test on the Top-Hat/Expert relative difference, under the hypothesis $\mathrm{H}_{0}: \mu=0$, is highly significant $(t=9.58$ significant at $\alpha=0.001$ ) and the same test on the Spectral/Expert relative difference is also significant $(t=3.11$ at $\alpha=0.01)$.

\section{Estimation of error sources}

The sources of errors are multiple and can be assigned to method-intrinsic causes, inappropriate otolith preparation and at worst from a sub-optimal demodulation (see figure 6) to an inappropriate growth model. In practice, the spectral method found most of the total increment estimation upon well defined increments and the a priori growth pattern. The number of non well defined increments is then estimated on this base. Any important departure from this framework would involve errors as described above, although the tolerance is large. The lack of any particular edge processing could also involve $a \pm 1$ day error (or \pm 1 year error in the case of the saithe). In the same way, the attribution of a constant duration to the pre-mouth-opening period, although it can be verified in experimental conditions ( 3 days \pm 0.5 for the Dover sole at $12^{\circ} \mathrm{C}$ and a $12: 12$ photoperiod), could be just an estimation of an in situ sample. In the case of the Dover sole, the growth model adequation could be questioned on several otoliths with numerous checks, which supposes a break in growth rhythm. Anyway, this source of error is not systematic. In the saithe case, the error source appears more systematically. Indeed, the model used is a VBGF, when the otolith growth pattern seems to be closer to a Gompertz growth pattern. The consequence is a sub-optimal signal demodulation which can lead to an under estimation of the ring number (estimated here at 1 year). In this special case the refinement of the growth parameter values would be inefficient or would even lead to biologically unrealistic results. The Top-Hat counting method is a reduction of the expert procedure insofar as it does not include any growth pattern representation. The curvilinear pattern of the relative errors shows an increase of the counting errors which is proportional to the signal length. This could be simply explained by the absence of dynamical information in the method definition. Thus, this classical method is very sensitive to the sharpness of the rings, and requires uninterrupted rings, a condition that is almost never fulfilled, and so requires constant operator verification. The complexity of the saithe otolith shape is probably a source of errors. This concept should be taken into account in any significant method improvement.

\section{Shape factor}

The reliability of the method on the Dover sole larvae otolith is duc to a convergence of favourable circumstances such as high contrasted increments, the shape simplicity and the occurrence of a reliable growth model. Nevertheless, in its present form, the spectral method only considers a monophased growth pattern and is only able to point out "abnormal" growing individuals indicating either an inappropriate growth law or a non-daily rate of increment formation. Three individuals with atypical growth pattern (wide increments) were identified with the spectral method and showed a lower accretion rate. The increment contrast could be significantly improved by otolith polishing. The representation of the polar coordinates and thus the use of radials included a circular accretion model corresponding rather well to the growth pattern of larval olotiths. The development of new deposition centres modifies the otolith shape ( fig. 10) and then tends to invalidate the polar model by creating metric distortions on the radials. Then, recourse to orthogonal trajectories instead of radials, either user defined or automatic, will be necessary. Concerning the saithe otolith, the distortion could be neglected, but in the case of large larval otoliths a user defined image profile could be an effective operation.

\section{Individual growth}

Numerical data acquisition enables us to have access to otolith measurements such as the distance from each increment to the nucleus. The introduction of a growth pattern also allows us to compute a relative growth trajectory which gives the intensity of individual departure from a reference growth law and 

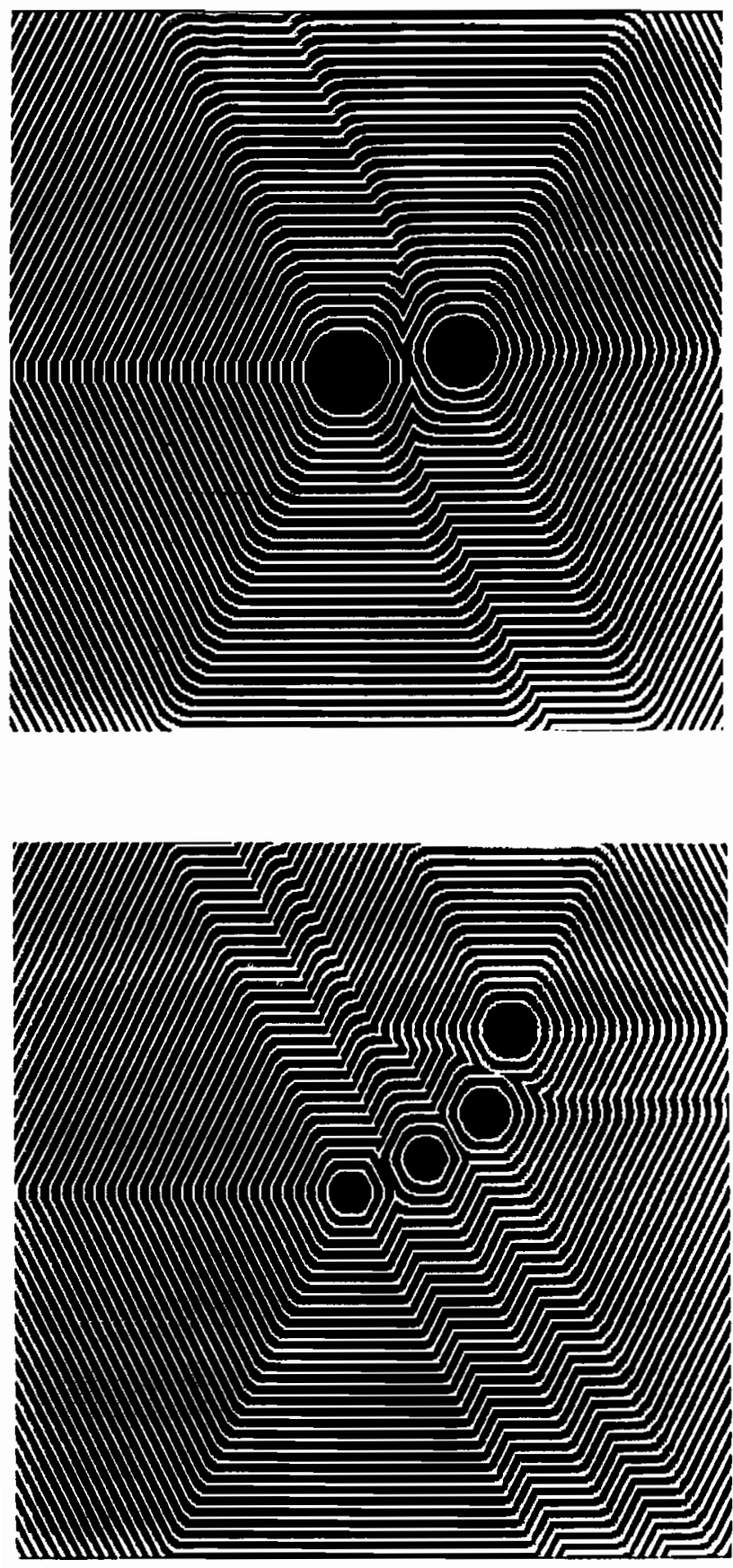

Figure 10. - Pluri-nuclear growth simulation with a distance function.

thus to identify a period of growth rate decreasing or increasing, as shown on figure 11. This could be compared to dendrochronology in which the signals is represented by a linear aggregated model. Here the residual component, unexplained by the model, is assimilated to an individual growth trajectory. In the case of perturbed growth pattern individuals, a refinement of the spectral analysis could be undertaken on scattered spectrum. In the case of unknown growth law individuals, the development of this concept

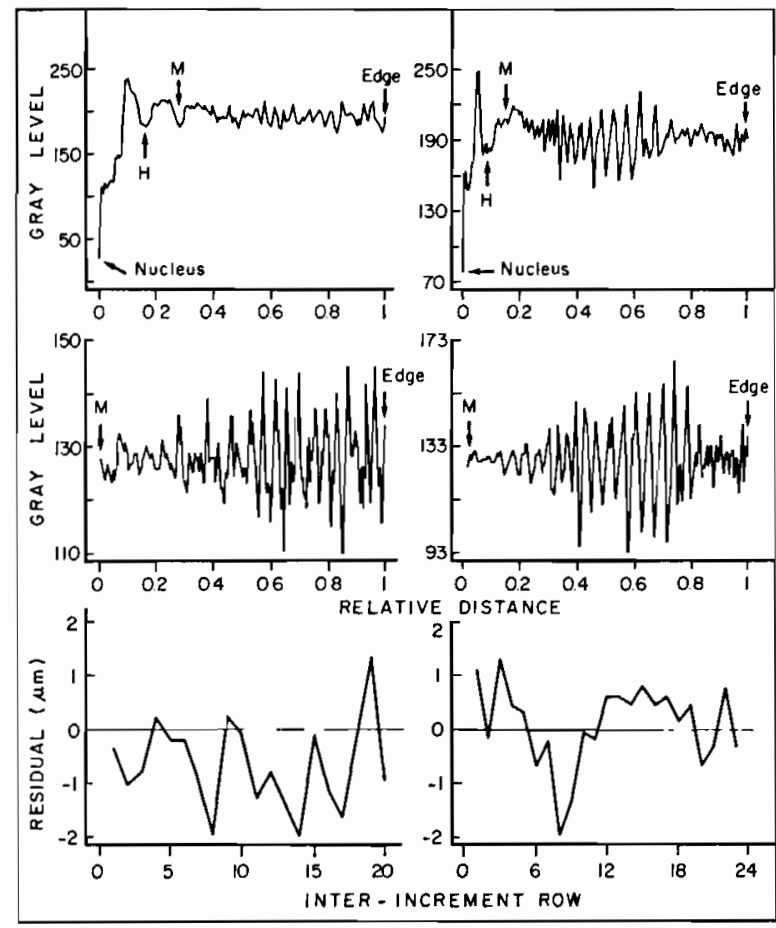

Figure 11. - Example of growth residuals computation on Dover sole larval otoliths. $(a)$ and $(b)$ synthetic radial $\mathrm{P}(r, \theta),(c)$ and $(d)$ filtered and anamorphosed $P(r, 0)$, (e) and ( $f)$ growth residuals. $H$ refer hatch check and $M$ to the mouth-opening check.

would be to demodulate the otolith signal without $a$ priori growth pattern. Indeed, signal processing demodulation techniques do not usually require any a priori modulating pattern, although the reference to a biological growth law would still be absolutely necessary.

\section{CONCLUSION}

Compared with semi-automatic image analysis systems we proposed:

- an automatic and fast $(<40$ seconds per otolith maximum) data acquisition and data processing algorithm reducing the operator intervention to the mere selection of a region of interest;

- an objective and reproducible reading technique;

- the introduction of biological knowledge ( $a$ priori growth pattern) and of spectral analysis allowing the counting of well defined increments and the estimation of poorly contrasted increments.

Regarding the Dover sole larval otolith, the order of precision is close to that of the expert and could be easily improved in the case of the saithe otolith by referring to a more adapted growth model and by developing a special edge ring processing. The method should be replaced in a more general C.s. reading 
framework. The nature of the information held by C.s. is multiple. We could distinguish the structural information, which is promoted in the literature, from the dynamical information, which is usually considered at the population level, and from the shape information. The case of the Dover sole and generally the case of the larval otoliths are characterized by elementary shapes growing most of the time, but not always, from a unique nucleation site. The saithe otolith, known to be without any peculiar reading difficulties, presents multiple nucleation sites whose zones of influence are observed on cross-sections. In our example, structural information has been discarded from automatic recognition by making it user defined. The acquisition of this information will probably be the most difficult step to automize because of the strong subjectivity or the fuzziness of their definitions compared with the growth pattern. Nevertheless all profitable advances should take into account:

- the multiple nature of the information, which refers to a general Pattern Recognition framework, even if some components are to be neglected afterwards;

- the difficulty to reduce the automation to a simple and literal translation of the expert reading scheme, which refers to a human-computer mutual performance analysis;

- the introduction of biological knowledge should not be restricted to numerical information but should be extended to a symbolic or logic knowledge constituting the major part of the human reading scheme. This would require recourse to artificial intelligence techniques.

Far from being restricted to light microscope imaging, this technique could be used equally on images from SEM, microprobe or any other potential numerical source. Nevertheless, the use of numerical images should not be restricted to the collection of measurements but should be the start of a conceptual framework of C.s. signal processing, as dendrochronologists have developed for tree rings.

\section{Acknowledgements}

Special thanks are due to F. Lagardère (CNRS-IFREMER, CREMA L'Houmeau) for her contribution to this work and to P. Neal (IPHC, Scattle) for reading and commenting the first draft of this paper.

\section{REFERENCES}

Anonymous, 1960. Report of subcommittce on ageing techniques. Report of the standing committce on Research and Statistics. Ann. Meet. int. Comm. Northw. Atlant. Fï.s., 37 p.

Anonymous, 1984, Atlantic Salmon scalc reading. ICES Report of the Atlantic Salmon scale reading workshop, Aberdeen 23-28 April 1984, $40 \mathrm{p}$.

Anonymous, 1988. Atlantic Salmon scale rcading, ICES Report of the Atlantic Salmon scale reading workshop, Aberdeen, $40 \mathrm{p}$.

Bcucher S., J. M. Blosseville, F. Lenoir, 1988. Traffic spatial measurements using video image processing. In: Image analysis and Mathematical Morphology, tome 2, Serra J., Academic Press.

Campana S. E., J. A. Gagné, J. Munro, 1987. Otolith microstructure of larval herring (Clupea harengus): image or reality? Can. J. Fish. Aquat. Sci., 44, 1922-1929.

Everson I., 1980. Méthodes de détermination de l’âge chez les poissons antarctiques, Cybium, 3, 41-59.

Frie R. V., 1982. Measurements of fish scales and backcalculation of body lengths using a digitizing pad and microcomputer. Fisheries, 7, 5-8.

Goncharov A. I., M. M. Smetanin, 1974. A method for objective detcrmination of the age of fish and study of their growth from the scales. Inform. hyul. In-ta biol. inutrennikh vod AN SSSR, 22, 63-67.
Hirschhorn G., G. J. Small, 1987. Variability in growth parameter estimates from scales of Pacific cod based on scale and area measurements. In: Age and Growth of Fish, R.C. Summerfelt R. C., G. E. Hall eds, Iowa State University Press, 147-158.

Jensen A. C., 1965. A standard terminology and notation for otolith readers. ICNAF Res. Bull., 2, 5-7.

Kohler A. C., 1964. 1963 ICNAF Cod otoliths exchange. ICNAF Res. Bull., 1, 22-27.

Lagardère F., 1989. Influence of feeding conditions and tempcrature on the growth rate and otolith-increment deposition for larval Dover Sole, Solea solea L., larvac. Rapp. P. v. Réun. Cons. Int. Explor. Mer, 191, 390-399.

Lea E., 1910. On the methods used in the Herring-investigations. Pub. Cire. Cons. Int. Expl. Mer, Copenhague, 53, 7-175.

McGowan M. F., E. D. Prince, D. W. Lee, 1987. An inexpensive microcomputer-based system for making rapid and precise counts and measurements of zonations in video displayed skeletal structures of fish. In: Age and Growth of Fish, R. C. Summerfelt R. C., G. E. Hall cds., Iowa State University Press, 385-395.

Mason J. E., 1974. A semiautomatic machine for counting and measuring circuli of fish scales. In: Ageing of Fish, T. B. Bagenal ed., Unwin Brothers Ltd. Londres, 87-102.

Messich S., C. McDougall, 1985. A computer based method for separating herring spawning groups using digitized otolith morphometrics. Canadian Atlantic Fisheries Scientific Advisory Committec, Res. Doc. 85/106, 1-13. 
Neal P. R., 1986. Automated aging of Pacific Halibut (Hyppoglossus stenolepis) otoliths using digital image analysis. MSc, Univ. Washington, $152 \mathrm{p}$.

Scrra J., 1986. Elements de théoric pour l'optique morphologique. Thèse dr. État Mathématiques. Univ. Paris-VI, $217 \mathrm{p}$.

Souplet A., J. L. Dufour, 1983. Développement des techniques de lecture des otolithes en coupes fines. Rupp. Techn. ISTPM, 5, $13 \mathrm{p}$.

Sych R., 1974. The source of errors in agcing fish and considerations on the proofs of rcliability. In: Ageing of Fish, T. B. Bagenal cd., Unwin Brothers Ltd. Londres, 78-86.

Troadec H., P. Prouzet, 1986. Essai de détermination de l'âge et de la croissance du Saumon atlantique (Salmo salar L.) par analyse d'image de leurs écailles. Cons. Int. Explor. Mer, Comité des poissons Anadromes et Catadromes, C.M. 1986/M: 14.

Troadec H., 1992. Reconnaissance de structures sur des pièces calcifiées par imagerie numérique dans un but de suivi d'un stock halieutique. Thèse dr. Univ. Paris-VII, Eiomathématiques, $257 \mathrm{p}$.

Tzeng W. N., S. Y. Yu, 1988. Daily growth increments in otoliths of milkfish, Chanos chanos (Forsskål), larvae. J. Fish. Biol., 32, $495-504$.

Vasil'kov V. P., 1977. The information-recording properties of the scales of the New-Zcaland Jackassifsh, Cheilodactylus macropterus, and their use to obtain information on growth rhythms. J. Ichtyol., 17, 375-381.

Vasil'kov V. P., 1979. The significance, nature and possible causes of growth rhythms in fish. J. Ichtyol., 19, 56-63. 